\title{
Investigations of Dynamic Behaviors of Face Gear Drives Associated with Pinion Dedendum Fatigue Cracks
}

\author{
Zhengminqing Li, Shuang Liu, Rupeng Zhu, and Xiaodong Xu \\ Nanjing University of Aeronautics and Astronautics, Nanjing, Jiangsu, China \\ Correspondence should be addressed to Zhengminqing Li; lzmq_cmee@nuaa.edu.cn
}

Received 10 March 2016; Revised 31 July 2016; Accepted 1 August 2016

Academic Editor: Ganging Song

Copyright ( 2016 Zhengminqing Li et al. This is an open access article distributed under the Creative Commons Attribution License, which permits unrestricted use, distribution, and reproduction in any medium, provided the original work is properly cited.

Face gear dynamics is addressed by many scholars. However, dynamic behaviors of face gear drives associated with pinion dedendum fatigue cracks are yet to be investigated. Thus, in the study, a calculation solution of static transmission errors (STE) of face gear drives associated with pinion dedendum fatigue cracks is constructed, based on the proposed equivalent face gear drives, and a four-degree-of-freedom (DOF) dynamic model of face gear drives is formulated. The dynamic behaviors of an example case of face gear drives associated with pinion dedendum fatigue cracks are investigated. The simulation results indicate natural frequencies of face gear drives would be decreased with pinion dedendum fatigue crack extensions; the relationship between accelerations and velocities of face gear drives, dynamic mesh forces, and vibration accelerations at bearings would also be changed. However, pinion dedendum fatigue cracks of face gear drives are detected difficultly, due to simulation result similarities. Therefore, a determination solution for pinion dedendum fatigue cracks of face gear drives is proposed. The result shows a trend of vibration accelerations at bearings, namely, a first decreasing and then increasing tendency, which could be beneficial to detecting pinion dedendum fatigue cracks of face gear drives. These contributions would improve engineering applications of face gear drives in the future.

\section{Introduction}

A face gear drive, which is a kind of intersection gear drives with an involute spur pinion, is one of the significant gear drives due to its insensitive characteristics of manufacture and alignment errors versus spiral bevel gear drives and is addressed by scholars. There are a vast number of manuscripts discussing face gear drives in the past few years. Litvin et al. investigated tooth modeling solutions, stresses, and tooth contact analyses (TCA) of face gear drives [1-4]. Li et al. constructed an equivalent face gear tooth modeling solution and discussed influences of geometry parameters on strengths of face gear drives [5]. Guingand et al. tested tooth bending stresses of face gear drives under a quasistatic experiment [6]. A research team as core of Litvin, according to their study achievements, formed a design handbook of face gear drives [7] and suggested face gear drives to be used in firststage gear drives of helicopter main gear boxes [8], namely, input-stage gear drives, which occupy high rotation speed characteristics. Due to the suggestion, face gear dynamics becomes one of the study focuses of face gear drives. Li et al. discussed dynamic behavior differences among three version face gear drives associated with high contact ratios [9]. Hu et al. evaluated impacts of mesh stiffness on dynamic behaviors of face gear drives [10]. Jin et al. established a nonlinear dynamic model of face gear drives [11]. Yang et al. assessed vibration and bifurcation characteristics of face gear drives $[12,13]$. Li et al. studied influences of sliding frictions on dynamic behaviors of face gear drives [14]. Wang et al. probed load sharing effects of a face gear split torque transmission system [15]. However, according to the limited published issues, solutions of introducing pinion dedendum fatigue cracks into dynamic behavior analyses of face gear drives are not to be constructed and dynamic behaviors of face gear drives associated with pinion dedendum fatigue cracks are yet to be investigated. Thus, in the study, a calculation solution of static transmission errors (STE) of face gear drives associated with pinion dedendum fatigue cracks, based on the proposed equivalent face gear drives, is constructed, a four-degreeof-freedom (DOF) dynamic model of face gear drives is 


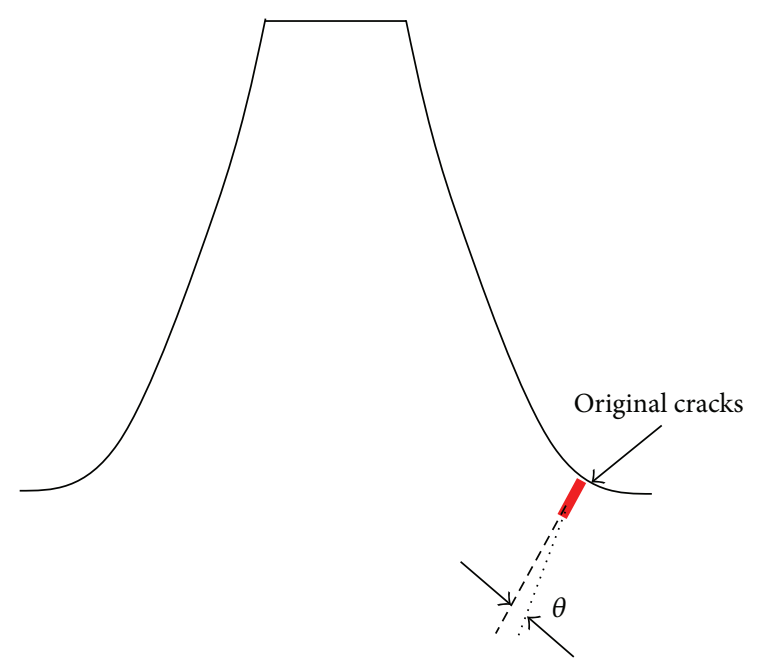

Figure 1: A sketch of pinion dedendum fatigue crack extension directions.

established, and the natural frequencies, dynamic behaviors, dynamic mesh forces, and vibration accelerations at bearings of an example case of face gear drives without and with pinion dedendum fatigue cracks are simulated. The results indicate that natural frequencies would be decreased with pinion dedendum fatigue crack extensions, and dynamic mesh forces, vibration accelerations at bearings, and relationships between accelerations and velocities of face gear drives would be changed with pinion dedendum fatigue crack extensions, but these dynamic behavior changes caused by pinion dedendum fatigue crack extensions are detected hardly, due to simulation result similarities. Therefore, a determination solution of pinion dedendum fatigue cracks of face gear drives is proposed and verified. These contributions would be beneficial to improving engineering applications of face gear drives in the future.

\section{Constructed Analysis Solutions}

2.1. STE Calculation Solution Associated with Pinion Dedendum Fatigue Cracks. Original pinion dedendum fatigue crack generations are random, due to influences of materials, manufactures, and operating conditions. Otherwise, pinion dedendum fatigue crack extension directions, as shown in Figure 1, can be predicted.

As shown in Figure 1, according to [17-19], crack extension angle $\theta$ can be expressed as

$$
\theta=\cos ^{-1}\left(\frac{3 k_{I I}^{2}+\sqrt{k_{I}^{4}+8 k_{I}^{2} k_{I I}^{2}}}{k_{I}^{2}+9 k_{I I}^{2}}\right),
$$

where $k_{I}$ is an opening-mode stress intensity factor and $k_{I I}$ is a sliding-mode stress intensity factor and, according to

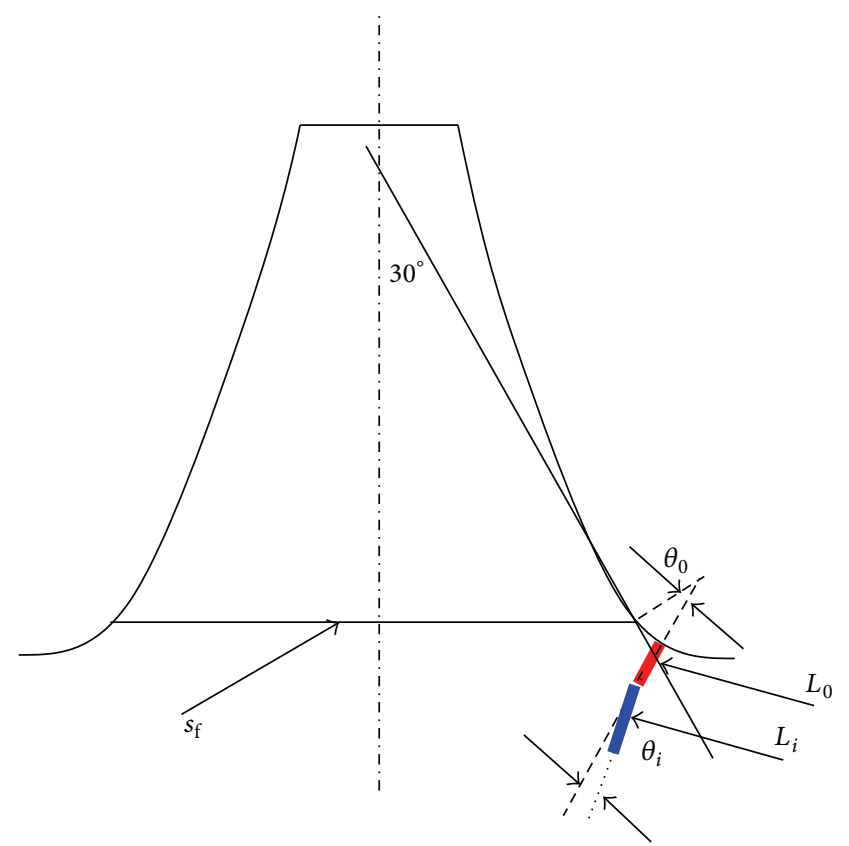

FIGURE 2: A sketch of influences of crack extensions on dedendum minimum life sections.

[17], both factors, based on finite element methods, can be calculated by

$$
\begin{aligned}
k_{I} & =\frac{2 G}{(3-4 \gamma)+1} \sqrt{\frac{\pi}{2 L}}\left(4 V_{d}-V_{e}-4 V_{b}+V_{c}\right), \\
k_{I I} & =\frac{2 G}{(3-4 \gamma)+1} \sqrt{\frac{\pi}{2 L}}\left(4 U_{d}-U_{e}-4 U_{b}+U_{c}\right),
\end{aligned}
$$

where $G$ is a shear modulus, $\gamma$ is Poisson ratio, $L$ is a finite element length, and $U$ and $V$ are symbols of finite element node displacements.

Meanwhile, an influence sketch of dedendum fatigue crack extensions on dedendum minimum life sections is shown in Figure 2.

As illustrated in Figure 2, $\theta_{0}$ is an original crack angle, $\theta_{i}$ is a crack extension angle of " $i$ " stage, $L_{0}$ is an original crack length, $L_{i}$ is a crack extension length of " $i$ " stage, and $s_{\mathrm{f}}$ is a dedendum minimum life section. After dedendum fatigue crack extensions, $s_{\mathrm{f}}$ becomes $s_{\mathrm{ff}}$, namely, a dedendum minimum life section associated with dedendum fatigue crack extensions, and based on the geometry relationship between fatigue crake extensions and dedendum minimum life sections, as shown in Figure 2, $s_{\mathrm{ff}}$ can be derived by

$$
s_{\mathrm{ff}}=s_{\mathrm{f}}-L_{0} \cos \left(30+\theta_{0}\right)-\sum_{i=1}^{n} L_{i} \cos \left(30+\theta_{0}+\theta_{i}\right),
$$

where symbol $n$ means stages and the dedendum minimum life section $s_{\mathrm{f}}$ can be calculated, according to [16].

Based on Ishikawa model and [20], pinion tooth flexibilities associated with dedendum fatigue cracks can be deduced as listed in Table 1. 
TABLE 1: Pinion tooth flexibilities associated with dedendum fatigue cracks.

\begin{tabular}{lc}
\hline Symbols & Equations \\
\hline$q_{\mathrm{Br}}$ & $\frac{12 \cos ^{2}\left(\omega_{x}\right)}{E s_{\mathrm{ff}}^{3}}\left(h_{x}^{2} h_{r}-h_{x} h_{r}^{2}+\frac{h_{r}^{3}}{3}\right)$ \\
\hline$q_{\mathrm{Bt}}$ & $\frac{6 \cos ^{2}\left(\omega_{x}\right)}{E s_{\mathrm{ff}}^{3}}\left(h_{i}-h_{r}\right)^{3}\left[\frac{h_{i}-h_{x}}{h_{i}-h_{r}}\left(4-\frac{h_{i}-h_{x}}{h_{i}-h_{r}}\right)-2 \ln \left(\frac{h_{i}-h_{x}}{h_{i}-h_{r}}\right)-3\right]$ \\
\hline$q_{\mathrm{G}}$ & $\frac{24 h_{x}^{2} \cos ^{2}\left(\omega_{x}\right)}{\pi E s_{\mathrm{ff}}^{2}}$ \\
\hline$q_{\mathrm{s}}$ & $\frac{2(1+\gamma) \cos ^{2}\left(\omega_{x}\right)}{E s_{\mathrm{ff}}}\left[h_{r}+\left(h_{i}-h_{r}\right) \ln \left(\frac{h_{i}-h_{x}}{h_{i}-h_{r}}\right)\right]$ \\
\hline
\end{tabular}

$q_{\mathrm{Br}}$ is a rectangle bending flexibility, $q_{\mathrm{Bt}}$ is a trapezoid bending flexibility, $q_{\mathrm{s}}$ is a share flexibility, $q_{\mathrm{G}}$ is a flexibility caused by tooth base rotations, and $E$ is an elastic modulus. Moreover, $h_{i}, h_{x}$, and $h_{r}$ are geometry parameters of pinions and $\omega_{x}$ is an acting angle. Both geometry parameters and acting angle can be calculated, according to [16].
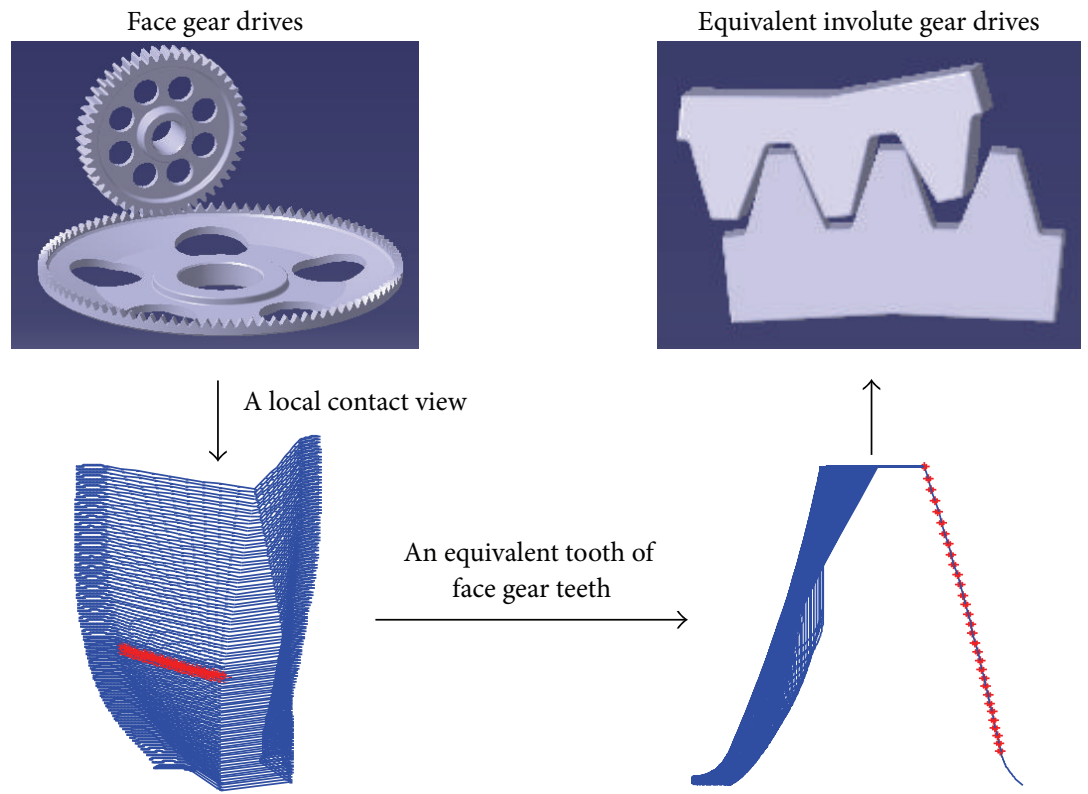

FIGURE 3: An evolution process of equivalent face gear drives.

Thus, based on the deduced pinion tooth flexibilities associated with dedendum fatigue cracks, as listed in Table 1 , and according to the relationship between flexibilities and deformations of gear teeth, a comprehensive deformation of pinion teeth associated with dedendum fatigue cracks can be obtained as

$$
D_{\mathrm{p}}=F\left(q_{\mathrm{Br}}+q_{\mathrm{Bt}}+q_{\mathrm{G}}+q_{\mathrm{s}}+q_{\mathrm{cl}}\right)
$$

where $F$ is a pinion tooth normal load and $q_{c 1}$ is a contact flexibility and can be expressed as [16]

$$
q_{\mathrm{c} 1}=\frac{\left(\left(\left(1-\gamma_{1}^{2}\right) / E_{1}\right)+\left(\left(1-\gamma_{2}^{2}\right) / E_{2}\right)\right)}{\pi},
$$

where subscripts 1 and 2 mean pinions and gears, respectively.

Based on the proposed solutions, pinion dedendum fatigue cracks could be introduced into involute gear tooth deformations, while face gear drives are not equal to involute gear drives. Thus, in order to introduce the proposed solutions into face gear drives, an equivalent face gear drive solution is presented, according to face gear tooth geometry characteristics.

A face gear drive can be equivalent as an involute gear drive in contact viewpoints, as shown in Figure 3, because a face gear tooth can be considered as a sequence in which modified involute gears are superimposed along its face width.

Meanwhile, STE of face gear drives, as shown in Figure 4, can be defined as a displacement deviation between actual contact points and theoretical contact points.

As given in Figure $4, r_{\mathrm{b} 1}$ and $r_{\mathrm{b} 2}$ are base circle radii of driving and driven gears, respectively, and STE of face gear drives $e$ can be written in

$$
e=D_{\mathrm{f}}-D_{\mathrm{p}}-\Lambda,
$$

where $D_{\mathrm{f}}$ is an equivalent face gear tooth deformation, which can be calculated according to (4), and $\Lambda$ is a comprehensive 


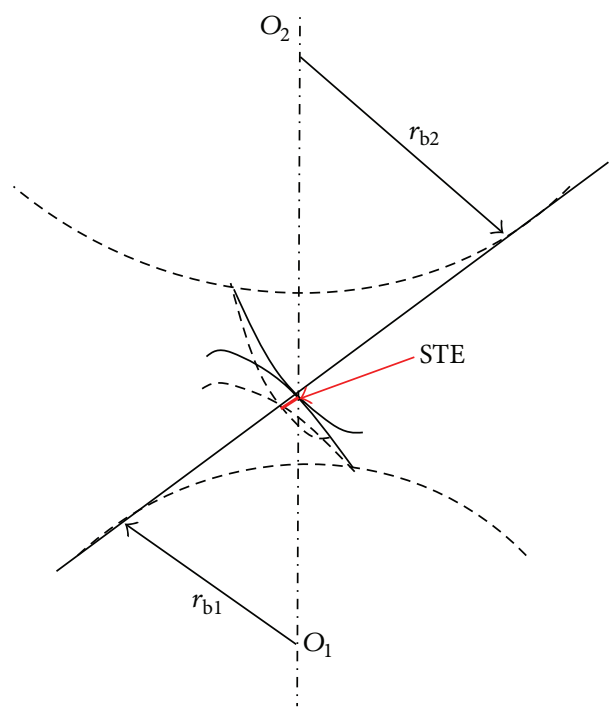

FIGURE 4: A sketch of STE of equivalent face gear drives.

meshing error caused by manufacture and alignment errors of face gear drives.

2.2. Dynamic Model. In order to investigate dynamic behaviors of face gear drives associated with pinion dedendum fatigue cracks, a four-DOF dynamic model of face gear drives is formulated, as shown in Figure 5.

As shown in Figure 5, according to Newtonian mechanics, mathematic equations of the four-DOF dynamic model can be derived by

$$
\begin{gathered}
m_{\mathrm{p}} s_{\mathrm{p}}^{\prime \prime}+c_{\mathrm{p}} s_{\mathrm{p}}^{\prime}+k_{\mathrm{p}} s_{\mathrm{p}}=-F_{\mathrm{m}}, \\
m_{\mathrm{f}} s_{\mathrm{f}}^{\prime \prime}+c_{\mathrm{f}} s_{\mathrm{f}}^{\prime}+k_{\mathrm{f}} s_{\mathrm{f}}=F_{\mathrm{m}}, \\
I_{\mathrm{p}} \theta_{\mathrm{p}}^{\prime \prime}+F_{\mathrm{m}} R_{\mathrm{bp}}=T_{\mathrm{p}}, \\
I_{\mathrm{f}} \theta_{\mathrm{f}}^{\prime \prime}+F_{\mathrm{m}} R_{\mathrm{bf}}=-T_{\mathrm{f}},
\end{gathered}
$$

where $F_{m}$ can be deduced as

$$
\begin{aligned}
F_{m}= & k_{\mathrm{m}} \sin (\gamma)\left(s_{\mathrm{p}}-s_{\mathrm{f}}+R_{\mathrm{bp}} \theta_{\mathrm{p}}-R_{\mathrm{bf}} \theta_{\mathrm{f}}-e\right) \\
& +c_{\mathrm{m}} \sin (\gamma)\left(s_{\mathrm{p}}^{\prime}-s_{\mathrm{f}}^{\prime}+R_{\mathrm{bp}} \theta_{\mathrm{p}}^{\prime}-R_{\mathrm{bf}} \theta_{\mathrm{f}}^{\prime}-e^{\prime}\right),
\end{aligned}
$$

where $R_{\mathrm{b}}$ is a base circle radius, $\theta$ is a torsion degree of freedom, $s$ is a bending degree of freedom, $T$ is a torsion, $k$ is a bending stiffness, $c$ is a bending damping, $m$ is a quality, $I$ is a moment of inertia, $\gamma$ is a shaft angle, ' is first derivative, "is second derivative, and subscripts $f$ and $p$ express a face gear and a pinion, respectively. In addition, $k_{\mathrm{m}}$ is mesh stiffness and $c_{\mathrm{m}}$ is mesh damping, which can be calculated, according to [16].

\section{Simulation and Analysis}

3.1. Pinion Dedendum Fatigue Crack Extension Simulations. In order to discuss impacts of pinion dedendum fatigue
TABLE 2: Parameters and operating conditions.

\begin{tabular}{lccc}
\hline & Names & Values & Units \\
\hline \multirow{2}{*}{ Geometry } & Pressure angle & 5 & $\mathrm{~mm}$ \\
parameters & Tooth number of the pinion & 25 & $\circ$ \\
& Tooth width of the pinion & 40 & $\mathrm{~mm}$ \\
& Tooth number of the face gear & 125 & - \\
\hline \multirow{3}{*}{ Geometry } & Internal radius of the face gear & 295 & $\mathrm{~mm}$ \\
parameters & External radius of the face gear & 330 & $\mathrm{~mm}$ \\
& Addendum coefficient & 1 & - \\
& Clearance coefficient & 0.25 & - \\
\hline Material & Elastic modulus & 210000 & $\mathrm{Mpa}$ \\
parameters & Poisson ratio & 0.3 & - \\
\hline Operating & Power & 500 & $\mathrm{~kW}$ \\
conditions & Input rotation speed & 20900 & $\mathrm{r} / \mathrm{min}$ \\
\hline
\end{tabular}

TABLE 3: Crack lengths and extension angles.

\begin{tabular}{lcc}
\hline Step & Crack length $L_{i}(\mathrm{~mm})$ & Crack extension angles $\theta_{i}\left(^{\circ}\right)$ \\
\hline 1 & 0.4 & 1.592 \\
2 & 0.8 & 3.326 \\
3 & 1.2 & 2.982 \\
4 & 1.6 & 2.735 \\
\hline
\end{tabular}

cracks on dynamic behaviors of face gear drives, an example case of face gear drives associated with pinion dedendum fatigue cracks is investigated, and geometry and material parameters and operating conditions of the example case are listed in Table 2.

In the simulation, an intersection point between minimum life sections and fillets is taken as the original point, and the crack length step is set as $0.4 \mathrm{~mm}$, which are determined by gear material characteristics and engineering experiences. Meanwhile, according to (1) and using 2D finite element method (FEM), whose setting is shown in Figure 6, the original fatigue crack is simulated, as shown in Figure 7.

In Figure 6, $q$ is an original point direction and $n$ is a normal direction to $q$. Based on the original fatigue crack, as shown in Figure 7, the fatigue crack extensions of the example case are simulated by FEM, as shown in Figure 8.

In the case of Figure 8 and according to the relationship between $\theta_{i}$ and $\theta_{0}$, as shown in Figure 2, the fatigue crack extension angles of the example case can be extracted, as listed in Table 3.

3.2. Dynamic Behavior Simulations. Employing (3) and the equations as listed in Table 1 and according to [16], the proposed equivalent face gear drives, as given in Figure 3, and the parameters as listed in Table 2, mesh stiffness of the example case of face gear drives associated with pinion dedendum fatigue cracks can be calculated. Then, introducing the mesh stiffness into (7), the natural frequencies of the example case are simulated, as shown in Figure 9. 


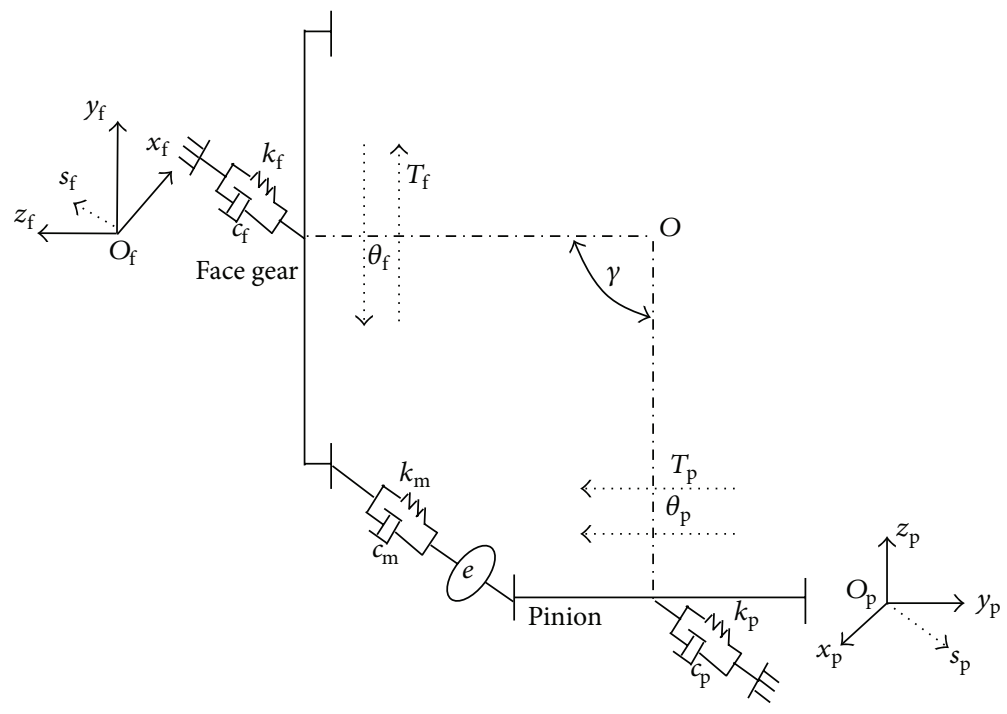

Figure 5: A four-DOF dynamic model of face gear drives.

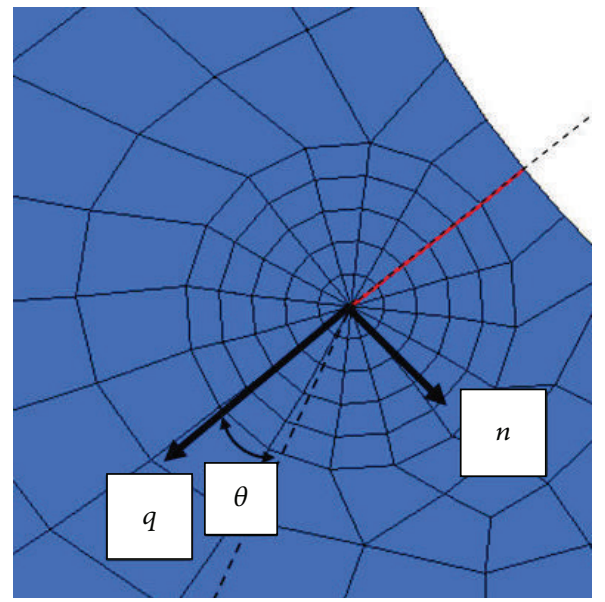

(a) The original point setting

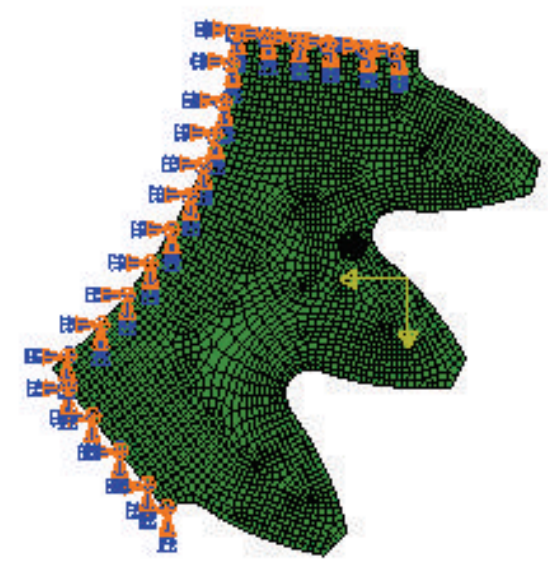

(b) The constraint setting

Figure 6: The 2D FEM settings.

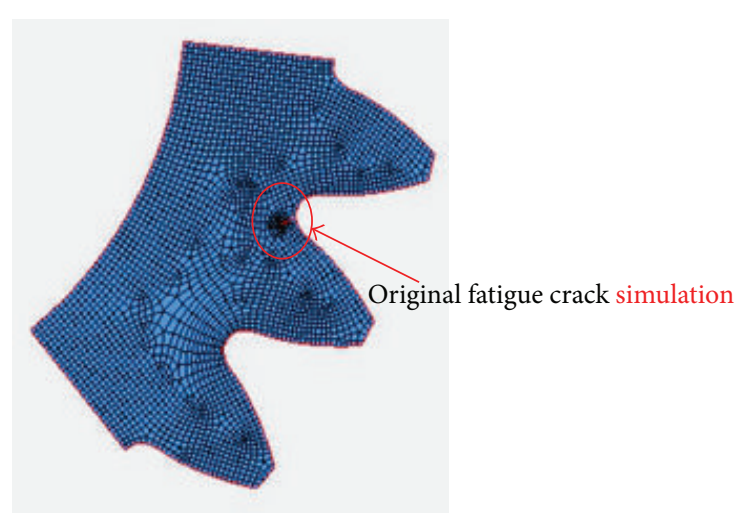

FIgURE 7: The simulation of the original fatigue crack of the example case. 


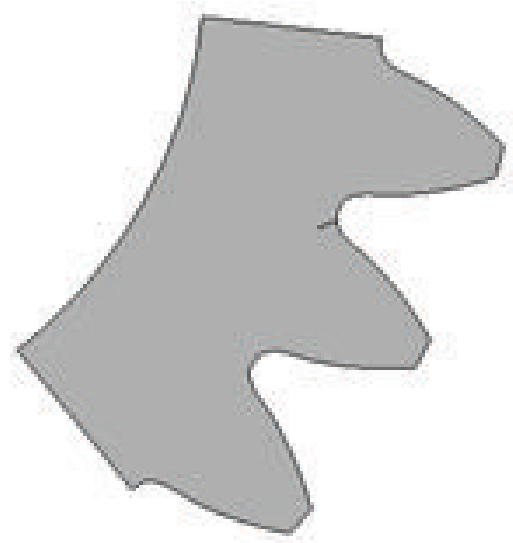

Step 1

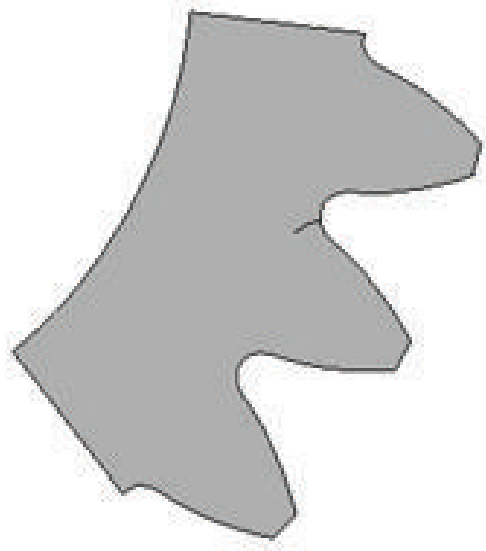

Step 3

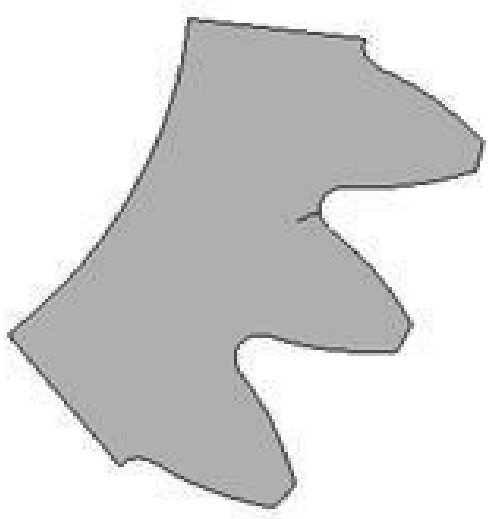

Step 2

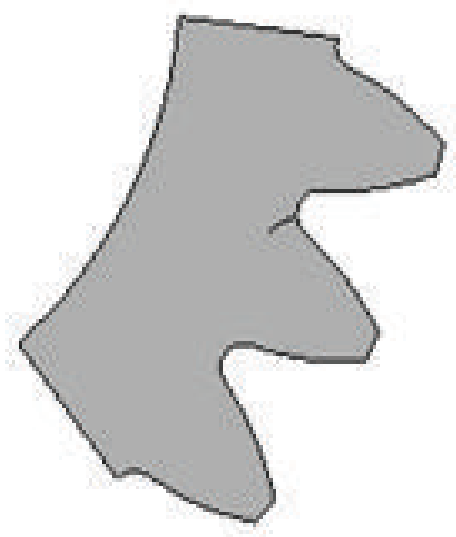

Step 4

FIgURE 8: The simulations of fatigue crack extensions of the example case.

As illustrated in Figure 9, natural frequencies of face gear drives would be decreased with pinion dedendum fatigue crack extensions.

According to (6), parameters as listed in Table 2, and the results of fatigue crack extensions, as listed in Table 3, the STE without and with pinion dedendum fatigue cracks of the example case is simulated, as shown in Figure 10.

Introducing the simulated STE, as shown in Figure 10, into (7), the dynamic behaviors of the example case of face gear drives associated with pinion dedendum fatigue cracks are given in Figures 11-13.

As shown in Figure 11, the relationship between accelerations and velocities of the example case of face gear drives associated with pinion dedendum fatigue cracks would be changed; that is, the escape phenomenon of small loops becomes more and more obvious. However, due to similar simulation results at any instance, the influence of pinion dedendum fatigue cracks on dynamic behaviors of face gear drives is not to be detected easily.

In the case of Figures 12 and 13, the dynamic mesh forces versus mesh frequency and the vibration accelerations at pinion remote bearings would be changed with the pinion dedendum fatigue cracks. However, whatever dynamic mesh forces or accelerations at bearings, the absolute values of the differences between drives without and with pinion dedendum fatigue cracks are very small, which also allowed discovering pinion dedendum fatigue cracks difficultly. Thus, based on the accelerations at pinion remote bearings and according to logarithm characteristics, namely, holding data properties and relationships, and compressing data scale, a pinion dedendum fatigue crack determination solution is constructed as

$$
d_{\mathrm{p}}=10 \log \left(\frac{\sqrt{\sum_{i=1}^{t} A_{i}^{2}}}{t}\right) \quad[1, t] \in \text { one cycle, }
$$

where symbol $t$ is a number of peaks and valleys of one cycle and $A_{i}$ is an amplitude of peaks or valleys of one cycle. According to (9) and Figure 13, $d_{\mathrm{p}}$ of the example case is simulated, as given in Figure 14.

As illustrated in Figure 14, with the crack extensions, the symbol $d_{\mathrm{p}}$ would first drop and then increase rapidly, which 

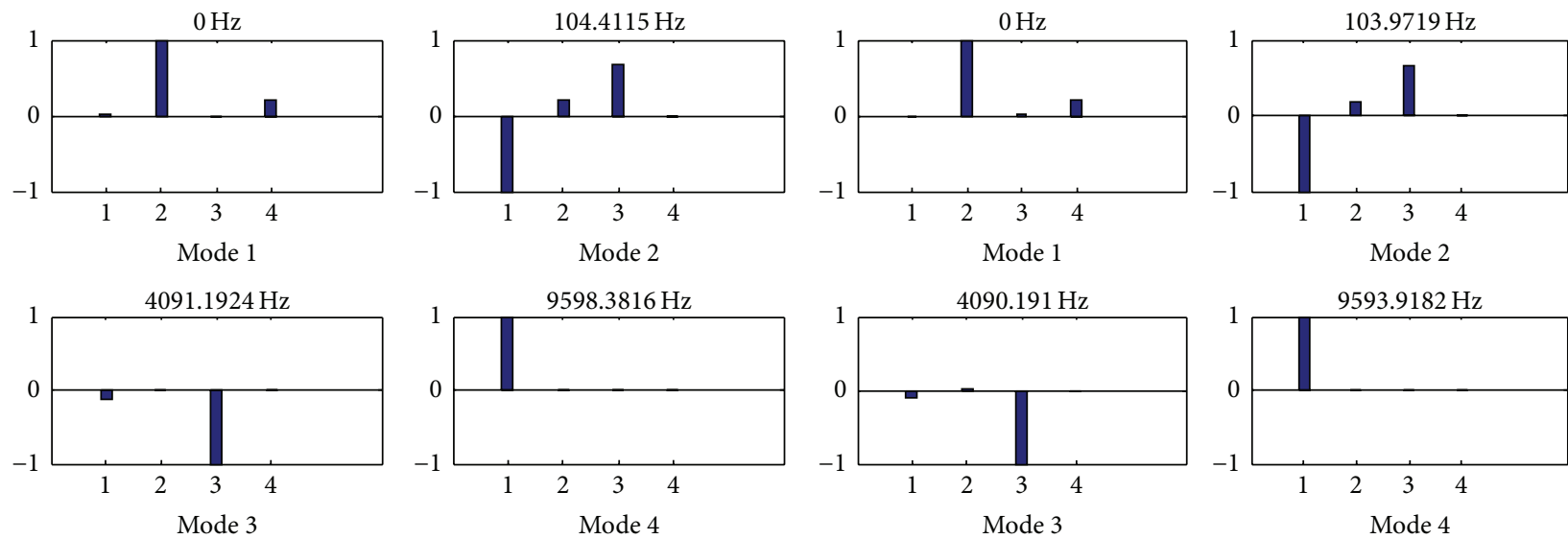

(a) Without any cracks
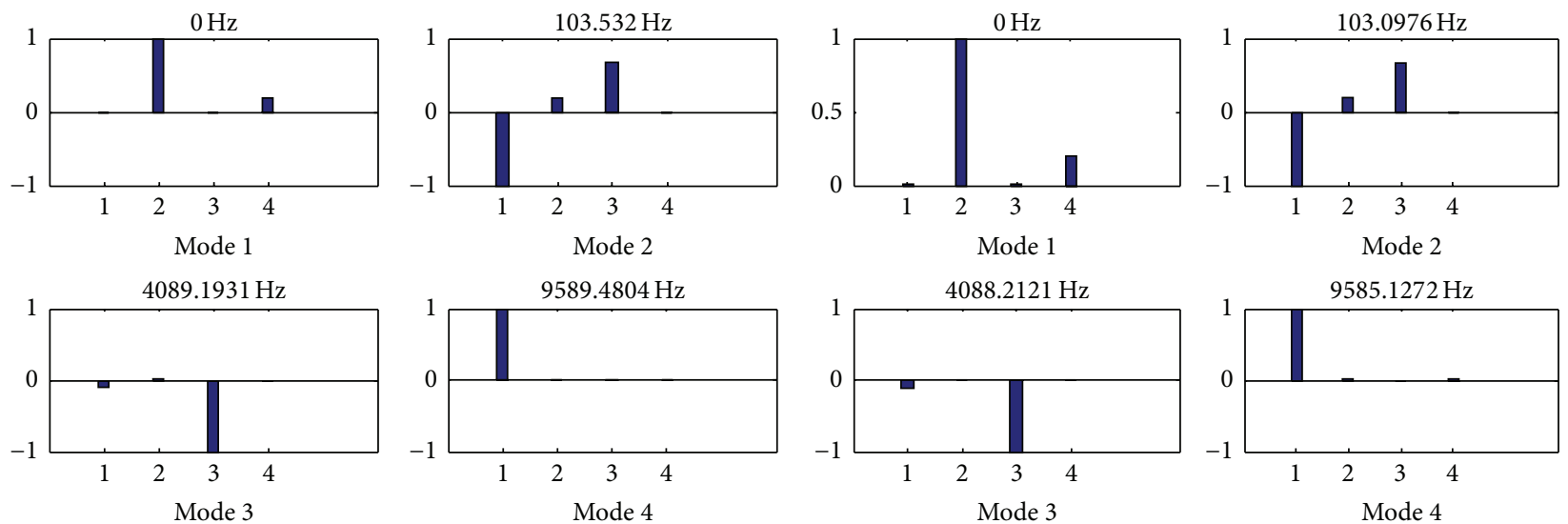

(c) With the second-step crack
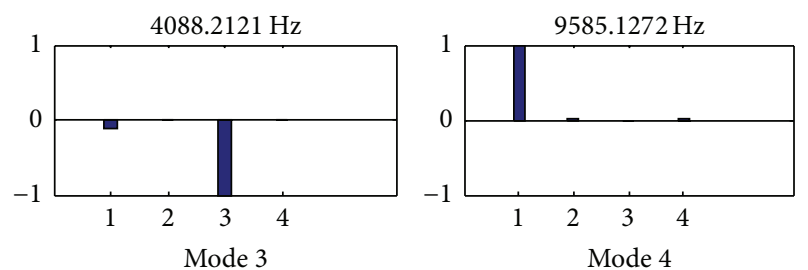

(d) With the third-step crack
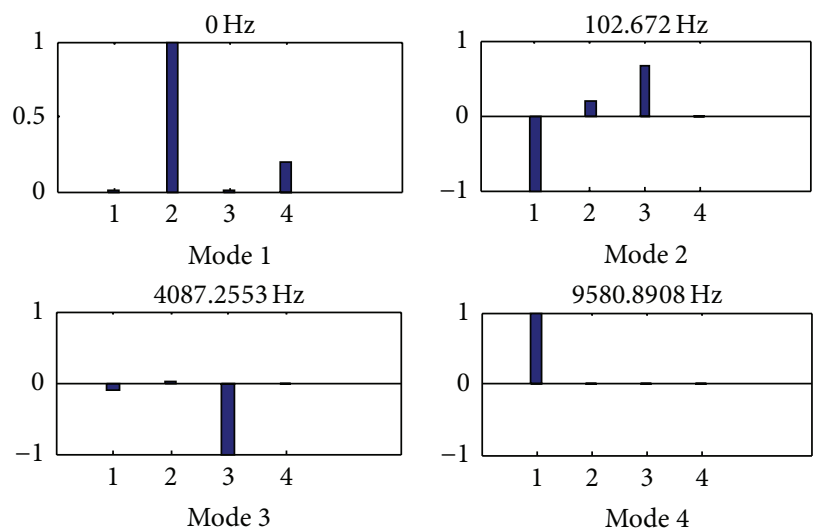

(e) With the fourth-step crack

FIGURE 9: The simulations of natural frequencies of the example case.

would help to detect pinion dedendum fatigue cracks of face gear drives.

\section{Conclusions}

In the study, three important works can be extracted as follows:
(1) A study solution of face gear dynamics considering pinion dedendum fatigue crack extensions is constructed, based on the proposed STE calculation solution of face gear drives associated with pinion dedendum fatigue cracks.

(2) Dynamic behaviors of face gear drives associated with pinion dedendum fatigue cracks are investigated by 


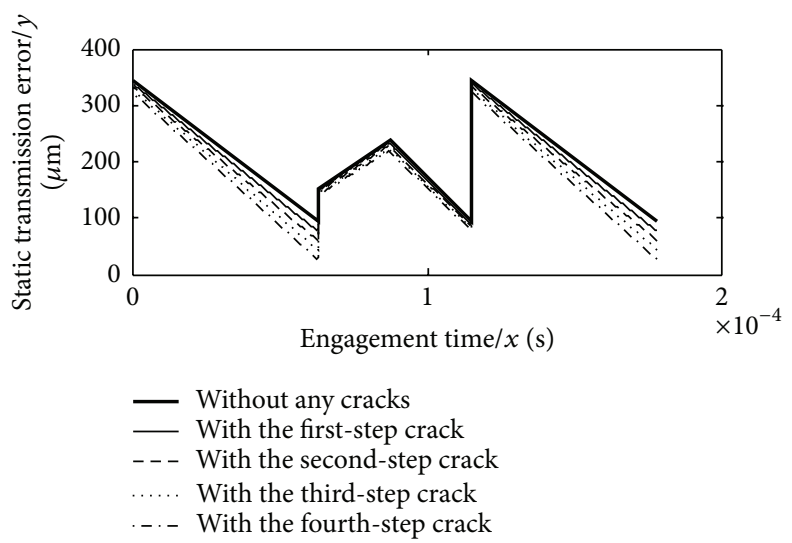

FIGURE 10: The simulation of the STE of the example case.

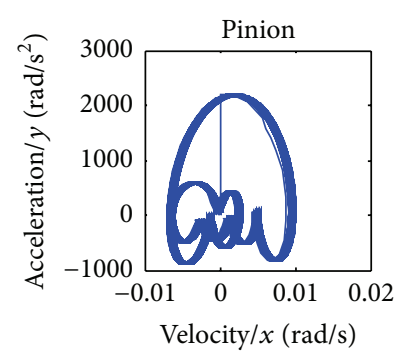

(a) Without any cracks

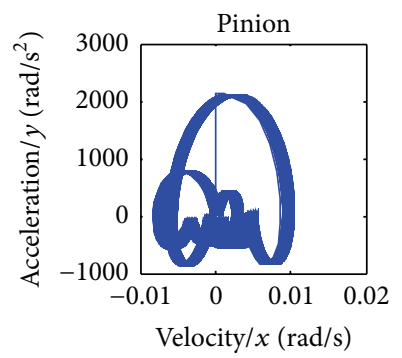

(c) With the second-step crack
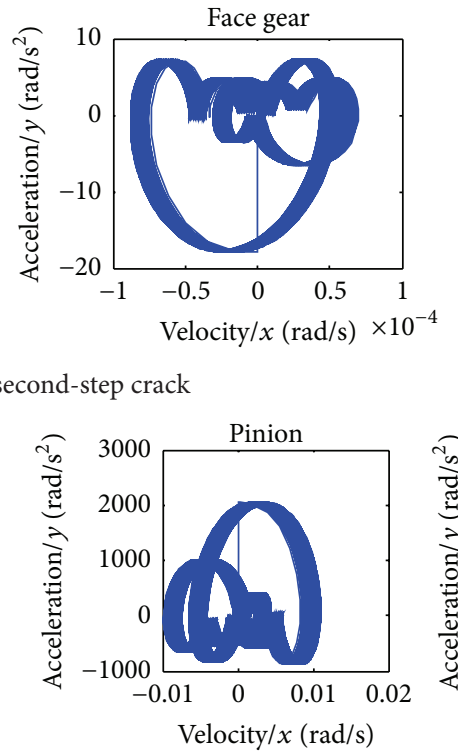

(e) With the fourth-step crack
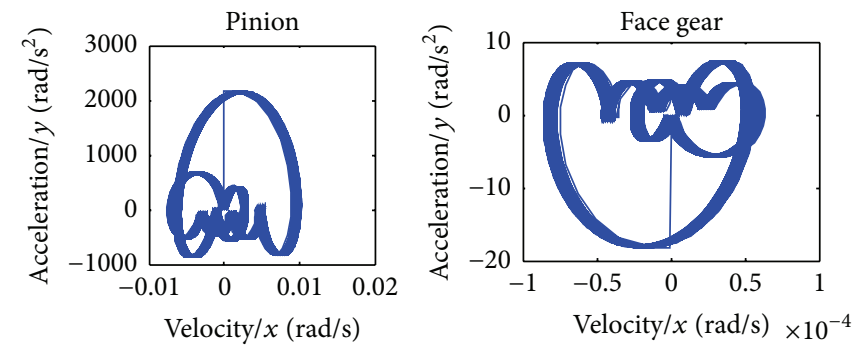

(b) With the first-step crack
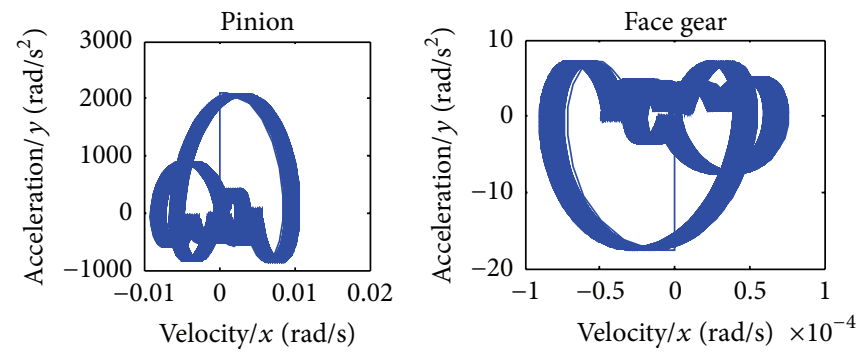

(d) With the third-step crack

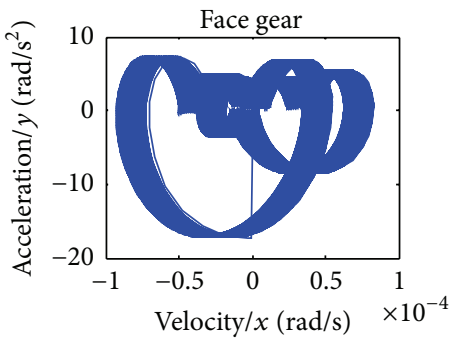

FIGURE 11: The simulations of the dynamic behaviors of the example case.

an example case simulation. The results indicate natural frequencies of face gear drives would be reduced with pinion dedendum fatigue crack extensions and the relationship between accelerations and velocities of face gear drives would be changed; that is, the escape phenomenon of small loops becomes obvious. Meanwhile, due to simulation result similarities at any instance, pinion dedendum fatigue cracks of face gear drives are not detected easily.

(3) A pinion dedendum fatigue crack determination solution is proposed and verified by the example case simulation. The results indicate the presented determination solution is accepted. 


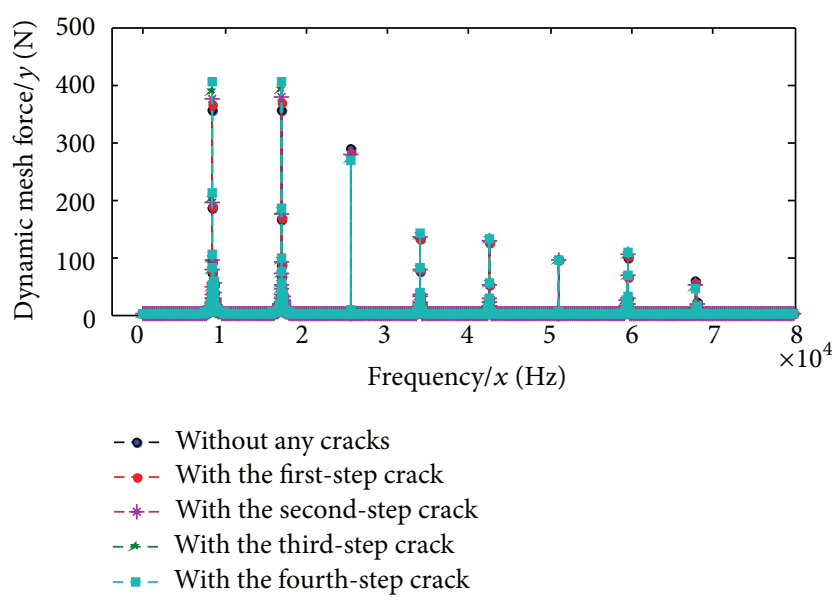

Figure 12: The simulation of dynamic mesh forces of the example case.

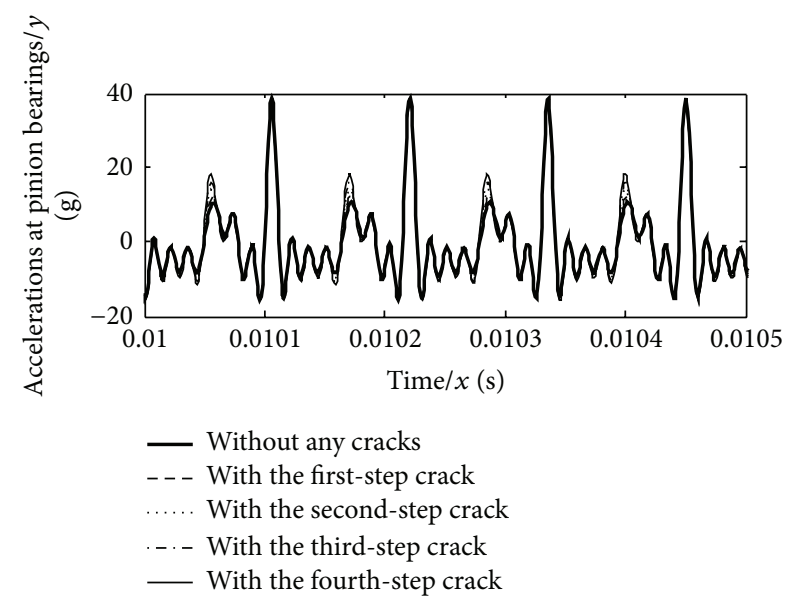

FIGURE 13: The simulation of pinion remote bearing accelerations of the example case.

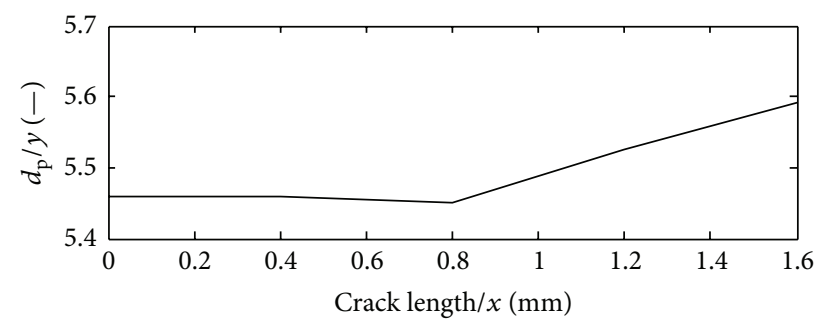

FIGURE 14: The simulation of $d_{\mathrm{p}}$ of the example case.

These contributions would improve engineering applications of face gear drives in the future.

\section{Competing Interests}

The authors declare that there is no conflict of interests regarding the publication of this article.

\section{Acknowledgments}

The authors are grateful for the financial support provided by the National Natural Science Foundation of China under Grant nos. 51105194 and 51375226 as well as the Fundamental Research Funds for the Central Universities under Grant nos. NS2015049, NS2015097, and NS2015054.

\section{References}

[1] F. L. Litvin, Y. Zhang, J.-C. Wang, R. B. Bossler Jr., and Y.-J. D. Chen, "Design and geometry of face-gear drives," Journal of Mechanical Design, vol. 114, no. 4, pp. 642-647, 1992.

[2] F. L. Litvin, A. Fuentes, and M. Howkins, "Design, generation and TCA of new type of asymmetric face-gear drive with modified geometry," Computer Methods in Applied Mechanics and Engineering, vol. 190, no. 43-44, pp. 5837-5865, 2001.

[3] F. L. Litvin, A. Fuentes, C. Zanzi, and M. Pontiggia, "Design, generation, and stress analysis of two versions of geometry of face-gear drives," Mechanism and Machine Theory, vol. 37, no. 10, pp. 1179-1211, 2002.

[4] F. L. Litvin, I. Gonzalez-Perez, A. Fuentes, D. Vecchiato, B. D. Hansen, and D. Binney, "Design, generation and stress analysis of face-gear drive with helical pinion," Computer Methods in Applied Mechanics and Engineering, vol. 194, no. 36-38, pp. 3870-3901, 2005.

[5] Z. Li, H. Wu, and R. Zhu, "Influence predictions of geometric parameters on face gear strength," Advances in Mechanical Engineering, vol. 7, no. 3, pp. 1-7, 2015.

[6] M. Guingand, J.-P. De Vaujany, and C.-Y. Jacquin, "Quasi-static analysis of a face gear under torque," Computer Methods in Applied Mechanics and Engineering, vol. 194, no. 39-41, pp. 4301-4318, 2005.

[7] F. L. Litvin, A. Egelja, J. Tan, D. Chen, and G. Heath, Handbook on Face Gear Drives with a Spur Involute Pinion, DTIC Document, 2000.

[8] F. Litvin, R. Bossler, Y.-J. Chen, D. Lewicki, G. Heath, and J.-C. Wang, "Application of face-gear drives in helicopter transmissions," Journal of Mechanical Design, vol. 116, no. 3, pp. 672-676, 1994.

[9] Z. Li, X. Liu, and R. Zhu, "Comparison of dynamic behaviors and strength among three versions of face gear drives with high contact ratios," Journal of Vibroengineering, vol. 17, no. 1, pp. 125136, 2015.

[10] Z. Hu, J. Tang, S. Chen, and D. Lei, "Effect of mesh stiffness on the dynamic response of face gear transmission system," Journal of Mechanical Design, Transactions of the ASME, vol. 135, no. 7, Article ID 071005, 2013.

[11] G.-H. Jin, R.-P. Zhu, and H.-Y. Bao, "Nonlinear dynamical characteristics of face gear transmission system," Journal of Central South University (Science and Technology), vol. 5, no. 41, pp. 1807-1813, 2010 (Chinese).

[12] Z. Yang, S.-M. Wang, Y.-S. Fan, and H.-X. Liu, "Bifurcation characteristics of face-gear transmission system," Journal of Harbin Institute of Technology, vol. 43, no. 3, pp. 107-110, 2011 (Chinese).

[13] Z. Yang, S.-M. Wang, Y.-S. Fan, and H.-X. Liu, "Vibration characteristics of face-gear transmission system with parametric excitation," Journal of Chongqing University, vol. 35, no. 1, pp. 26-35, 2011 (Chinese). 
[14] X.-Z. Li, R.-P. Zhu, Z.-M. Li, and G.-H. Jin, "Influences of frictional coefficient on vibration characteristic of face-gear transmission system," Journal of Vibration Engineering, vol. 27, no. 4, pp. 583-588, 2014 (Chinese).

[15] R. Wang, N. Zhao, L. Tao, Q. Jia, and H. Guo, "Floating shaft load sharing method for face gear split torque transmission system," Research Journal of Applied Sciences, Engineering and Technology, vol. 5, no. 12, pp. 3386-3392, 2013.

[16] X.-L. Zhu and E. Zhongkai, Analysis of Load Capacity of Gears, Higher Education Press, Beijing, China, 1992 (Chinese).

[17] J. Kramberger, M. Šraml, S. Glodež, J. Flašker, and I. Potrč, "Computational model for the analysis of bending fatigue in gears," Computers \& Structures, vol. 82, no. 23-26, pp. 22612269, 2004.

[18] J. Chen and S.-S. Zhao, Fracture Mechanics, Science Press, Beijing, China, 2006 (Chinese).

[19] A. T. Zehnder, Fracture Mechanics, Springer, Berlin, Germany, 2012.

[20] J. L. Shi, X. G. Ma, C. L. Xu, and S. J. Zang, "Meshing stiffness analysis of gear using the Ishikawa method," Applied Mechanics and Materials, vol. 401-403, pp. 203-206, 2013. 


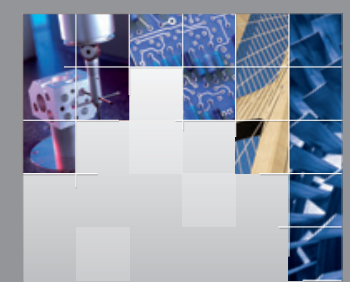

\section{Enfincering}
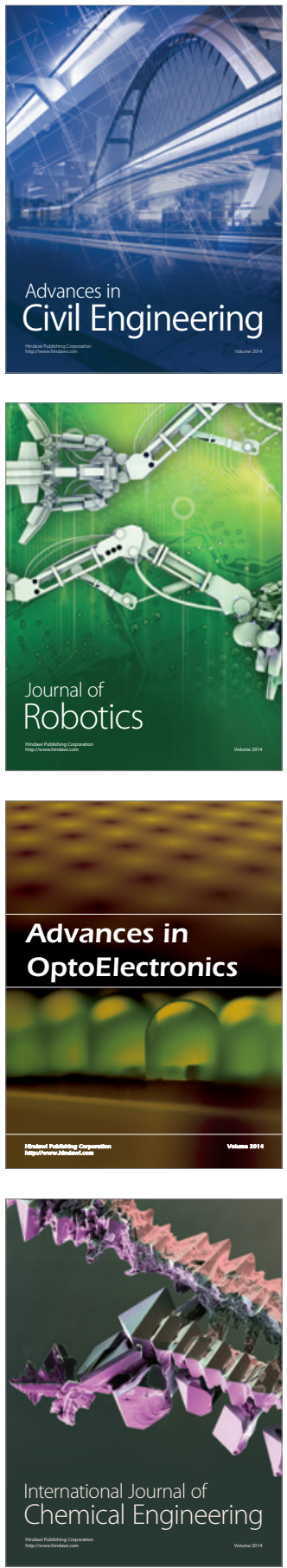

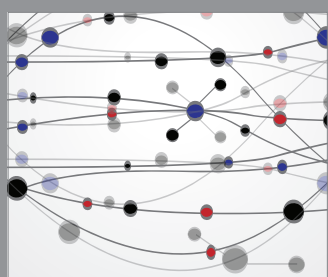

The Scientific World Journal

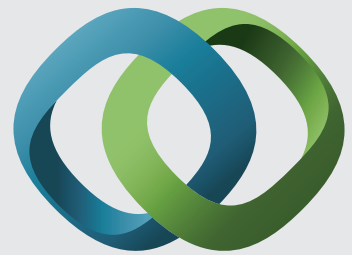

\section{Hindawi}

Submit your manuscripts at

http://www.hindawi.com
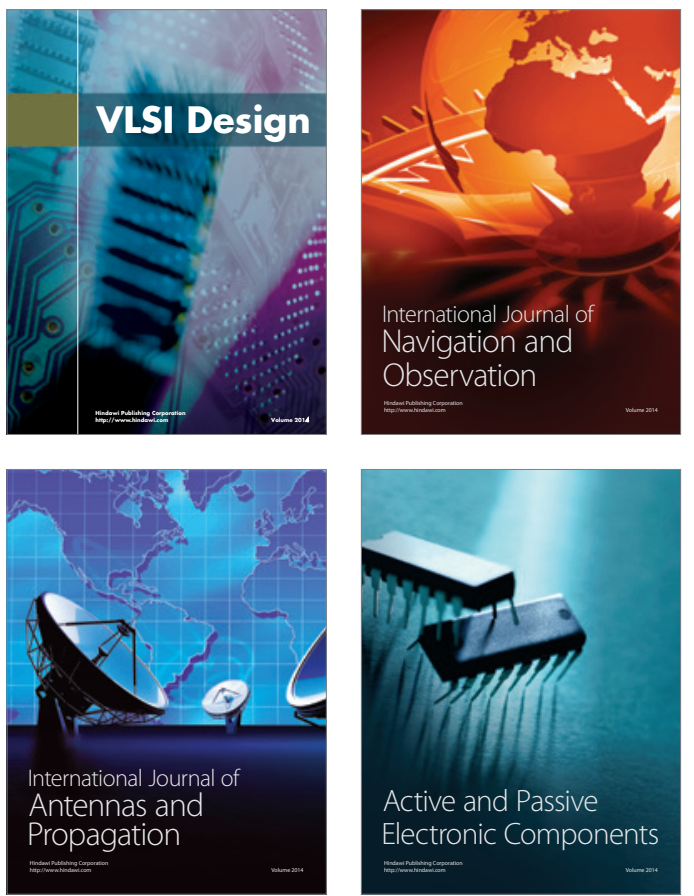
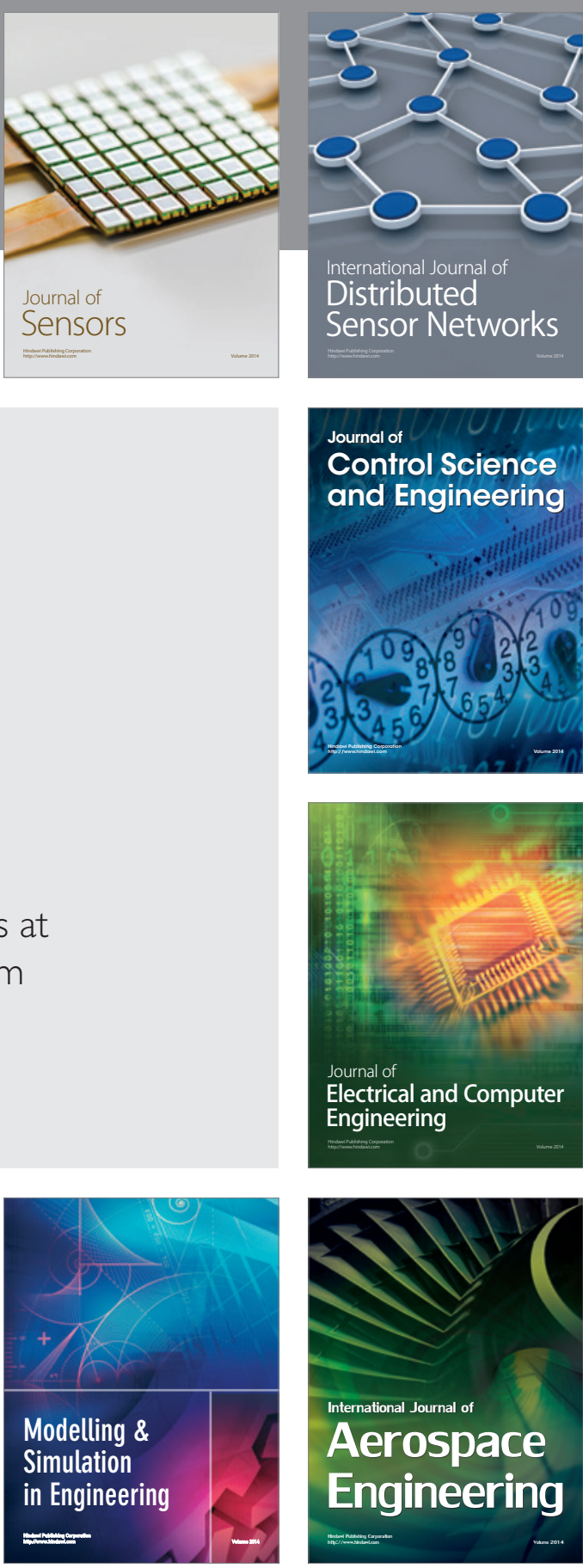

International Journal of

Distributed

Sensor Networks

Journal of

Control Science

and Engineering
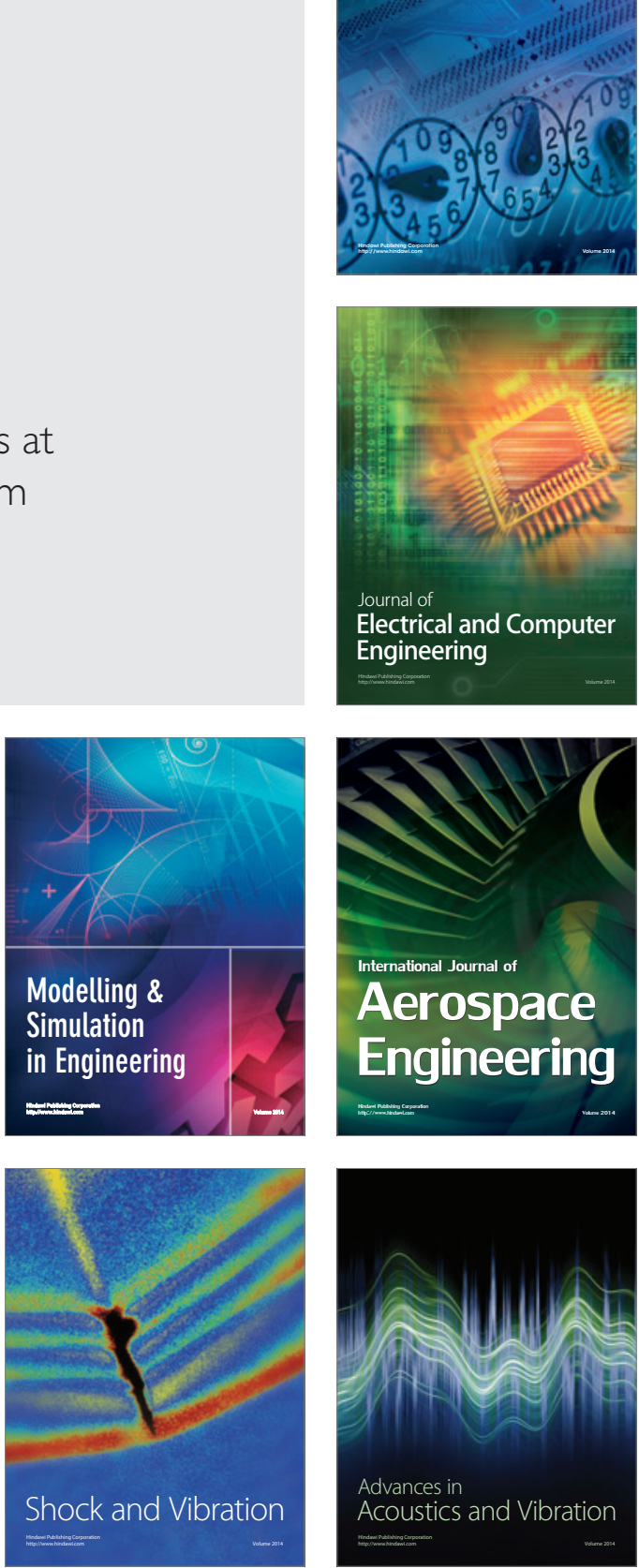